\title{
DI and D2 Receptor Antagonist Injections in the Prefrontal Cortex Selectively Impair Spatial Learning in Mice
}

\author{
Arianna Rinaldi', Silvia Mandillo ${ }^{1,2}$, Alberto Oliverio ${ }^{1,3}$ and Andrea Mele ${ }^{*, 1,3}$ \\ 'Dipartimento di Genetica e Biologia Molecolare, Università di Roma 'La Sapienza', Rome, Italy; 'Istituto di Biologia Cellulare-CNR, Campus A. \\ Buzzati-Traverso, Rome, Italy; ${ }^{3}$ Istituto di Neuroscienze-CNR, Psicobiologia, CERC, Rome, Italy
}

\begin{abstract}
The prefrontal cortex (PFC) is a cortical area involved in selecting and retaining information to produce complex behaviors. Within the PFC, the dopaminergic system plays an important role in information processing. Thus, the objective of this study was to test whether bilateral administration of the DI and D2 receptor antagonists in the prelimbic region of the PFC influenced the performance of mice in a non-associative spatial learning task. CDI mice were bilaterally microinjected in the PFC with either the DI receptor antagonist, SCH23390 (SCH 6.25; 12.5; 50 ng), or the D2 receptor antagonist, sulpiride (SULP 12.5; 50; 100 ng) and placed into an open field containing five different objects. After three sessions of habituation two objects were repositioned (spatial change) and in the subsequent session one of the objects was substituted (non-spatial change). No significant alteration was observed in the habituation pattern of the animals after DI or D2 receptor blockade. When two of the objects were displaced, control mice explored the displaced objects far more than the non-displaced ones, while mice treated with SCH or SULP spent a comparable amount of time re-exploring the two object categories. Conversely, DA antagonists had no effects on the discrimination of the new object. Thus, the administration of both SCH and SULP selectively impaired the ability of mice to discriminate a spatial change, without affecting any other behavioral parameter. These findings could provide a model to study the role of the PFC dopaminergic system in spatial learning and to study the neural mechanisms underlying cognitive and attention deficits often observed in psychiatric disorders.

Neuropsychopharmacology (2007) 32, 309-319. doi:I0.1038/sj.npp. I 301 176; published online 9 August 2006
\end{abstract}

Keywords: sulpiride; SCH 23390; spatial learning; prelimbic cortex; schizophrenia

\section{INTRODUCTION}

Dopamine (DA) has been involved primarily in motor and motivational functions (Robbins and Everitt, 1996; Wise, 2004). Nevertheless, recent evidence suggest that the dopaminergic system might also play an important role in modulating learning and memory (Whishaw and Dunnett, 1985; Ploeger et al, 1992; Mele et al, 1996; Roullet et al, 1996; El-Ghundi et al, 1999; Adriani et al, 2000; Glickstein et al, 2002).

The dopaminergic system consists of different pathways arising from the mesencephalon and innervating several forebrain regions differentially involved in spatial learning, such as nucleus accumbens, striatum, hippocampus, and prefrontal cortex (PFC). In particular, the mesocortical dopaminergic system originates from the ventral tegmental

*Correspondence: Professor A Mele, Dipartimento di Genetica e Biologia Molecolare, Università di Roma 'La Sapienza', P.le A. Moro 5 , 00185 Roma, Italy, Tel: + 3906 499| 2244, Fax: + 3906 499| 2800, E-mail: andrea.mele@uniromal.it

Received 2 December 2005; revised 20 April 2006; accepted 18 May 2006

Online publication: 6 July 2006 at http://www.acnp.org/citations/ Npp070606050708/default.pdf area (VTA), projects mainly to the PFC (Berger et al, 1974; Lindvall et al, 1974) and it plays a critical role in modulating prefrontal functions (Robbins, 2000).

The involvement of the PFC in spatial learning has been demonstrated in lesion studies using the Morris water maze (Sutherland et al, 1982; Kolb, 1984), the radial arm maze (Seamans et al, 1995; Floresco et al, 1997) and the object displacement in the open field (Sargolini et al, 1999). It should be noted, however, that the literature is not always consistent in indicating a role for this structure in spatial information processing (Poucet, 1989; de Bruin et al, 1994, 2001; Delatour and Gisquet-Verrier, 1996; Granon et al, 1996; Lacroix et al, 2002).

Similarly, contradictory results on a possible role of the mesocortical dopaminergic system in modulating spatial learning have been found. Intra-prefrontal administration of D1 antagonist SCH 23390, but not the D2 antagonist sulpiride, has been shown to induce an impairment in the delayed spatial win-shift version of radial arm maze in rats (Seamans et al, 1998). Neither SCH 23390 nor sulpiride injections into the PFC have affected the performance of rats in the delayed spatial alternation task (Romanides et al, 1999). On the other hand, intraprefrontal administration of the D1 agonist SKF 
81297 did induce a deficit in the same task in rats (Zahrt et al, 1997).

The purpose of the present work was to investigate the role of mesocortical dopaminergic system in spatial learning by pharmacological manipulation of DA receptors in the PFC in mice. Both D1 and D2 families of DA receptors are present in rodent PFC (Dawson et al, 1986; Vincent et al, 1993; Lidow et al, 2003) and the density of D1 receptors appears to be higher than that of D2 receptors both in rodents (Gaspar et al, 1995) and non-human primates (Lidow et al, 1991). Thus, we examined the effect of bilateral administration of D1 receptor antagonist SCH 23390 and D2 receptor antagonist sulpiride in the prelimbic region of the $\mathrm{PFC}$ of mice on their performance in a non-associative spatial learning task.

The task consists of a training phase in which the animals are placed into an open field containing five different objects. Mice are allowed to explore the open field and the objects for three consecutive sessions of habituation. Subsequently, in the test session, the reaction of mice to a spatial change is assessed after displacing two of the objects. Finally the reaction to a non-spatial change is examined by substituting a novel object for a familiar one. Control mice usually spend more time exploring the displaced objects (DO) as well as the novel one compared to the other objects. This response is interpreted as an index of rodent's ability to encode (or use) spatial and non-spatial relationships between discrete stimuli (Poucet, 1989; Save et al, 1992; Roullet et al, 1996). This task does not involve an explicit reinforcement and does not involve learning of rules, but it is based entirely on the spontaneous exploratory behavior of animals toward objects.

We chose to study the prelimbic (PL) region of the PFC based on previous behavioral and anatomical data, showing that the PL cortex is involved in spatial learning (Brito and Brito, 1990; Seamans et al, 1995, 1998; Sargolini et al, 1999). Moreover the PL is the prefrontal terminal area that receives the most dense glutamatergic projection from the hippocampus (Jay and Witter, 1991; Carr and Sesack, 1996) and dopaminergic projections from the VTA (Lindvall et al, 1974; Van Eden et al, 1987).

\section{MATERIALS AND METHODS}

\section{Subjects}

Subjects were CD1 male mice (Charles River, Calco, Italy). Upon arrival animals were 5-6 weeks of age and were housed in groups of three in standard breeding cages $(26 \times 20 \times 14 \mathrm{~cm})$, placed in a rearing room with a $12: 12 \mathrm{~h}$ light:dark cycle (lights on 07:30-19:30), at a constant temperature $\left(22 \pm 1^{\circ} \mathrm{C}\right)$, with food and water ad libitum. At the beginning of the experiment the mice were 9-10 weeks old and their weights ranged from 36 to $42 \mathrm{~g}$.

The study was conducted according to Italian and European laws and regulations on the use of animals in research and NIH guidelines on animal care.

\section{Surgery}

Mice were anaesthetized with an intraperitoneal injection of chloral hydrate $(500 \mathrm{mg} / \mathrm{kg}$, Fluka, Milan, Italy) and placed in a stereotaxic apparatus (David Kopf Instruments, Tujunga, CA, US). Two guide cannulas $(7 \mathrm{~mm}$ in length, $0.5 \mathrm{~mm}$ in diameter) were inserted bilaterally with the tip $1 \mathrm{~mm}$ above the prelimbic region of the PFC, using standard stereotaxic technique. The cannulas were fixed to the skull using dental acrylic (Shofu Inc., Kyoto, Japan). The following stereotaxic coordinates, with bregma and lambda in the same horizontal plane, were used: $+2.1 \mathrm{~mm}$ anterior to bregma, $\pm 0.5 \mathrm{~mm}$ lateral to midline, $-1.2 \mathrm{~mm}$ ventral from the skull surface (at bregma level), in accordance with the mouse brain atlas (Franklin and Paxinos, 1997) (Figure 2).

The subjects were then left in their home cage for a recovery period of 6-8 days.

\section{Drugs}

The drugs administered were the D1 dopamine receptor antagonist SCH 23390 (SCH) (Sigma, Milan, Italy) and the D2 dopamine receptor antagonist sulpiride (SULP) (Sigma, Milan, Italy).

SCH 23390 was dissolved in saline solution $0.9 \%(\mathrm{NaCl}$ $9 \mathrm{~g} / \mathrm{l}$ in distilled water) and administered at the doses of $6.25,12.5$, and $50 \mathrm{ng} / \mathrm{side}$. Sulpiride was dissolved in a minute volume of acetic acid and diluted with saline solution $0.9 \%$ to the final concentrations ( $\mathrm{pH}$ was adjusted to 7.0 with $\mathrm{NaOH}$ ). Sulpiride was administered at doses of $12.5,50$, and $100 \mathrm{ng} /$ side. Drug-treated mice were compared with saline or vehicle-treated control mice. Mice were tested only once.

\section{Experimental Apparatus}

The apparatus was a circular open field, $60 \mathrm{~cm}$ in diameter with a $20 \mathrm{~cm}$ high wall made of plastic material. Part of the wall was covered by a striped pattern, $30 \mathrm{~cm}$ wide and $20 \mathrm{~cm}$ high (alternating $1.5 \mathrm{~cm}$ wide vertical white and black bars). The floor was made of transparent Plexiglas placed on a white paper sheet divided into sectors by black lines. The open field was placed into a sound-proof cubicle. The apparatus was illuminated by a red light $(80 \mathrm{~W})$ located on the ceiling. A video camera placed above the open field was connected to a video-recorder and a monitor.

Five objects, differing by shape and material, were used in the open field: cone, a plastic cone on a transparent cylinder base (diameter $8 \mathrm{~cm}$; height $7 \mathrm{~cm}$ ); E-shape, a stainless-steel narrow and tall plate (height $10 \mathrm{~cm}$; width $4 \mathrm{~cm}$ ) with three smaller plates perpendicular to the first one (height $10 \mathrm{~cm}$; width $2 \mathrm{~cm}$ ); cube, a chromium-plated high parallelepiped $(4 \times 4 \times 7 \mathrm{~cm})$ with small holes irregularly distributed on the sides and the top; spool, a gray PVC spool (height $9 \mathrm{~cm}$; diameter of the top and the base $5 \mathrm{~cm}$ ); cylinder, a black PVC cylinder (height $10 \mathrm{~cm}$, diameter $5 \mathrm{~cm}$ ). A sixth object, an angle made of two regularly pierced iron plates (height $10 \mathrm{~cm}$; width $3 \mathrm{~cm}$ ) forming a $90^{\circ}$ angle, was used to test the reactivity to a new object.

\section{Intracerebral Injection and Behavioral Testing Procedure}

The behavioral testing procedure was that described by Save et al (1992) for rat and by Roullet et al (1996) for mice 
(Figure 1). On the test day, each mouse was placed individually into the empty open field for a 6 min session (S1), in order to become familiar with the apparatus. In the $\mathrm{S} 1$, the baseline level of locomotor activity was also scored. The mouse was then placed back into a holding cage for the injection. Microinjections were made by inserting an injection needle ( $8 \mathrm{~mm}$ in length, $0.25 \mathrm{~mm}$ in diameter) through each guide cannula. The injection needle was connected to a $2-\mu \mathrm{l}$ Hamilton syringe through a polyethylene tubing. A volume of $0.2 \mu \mathrm{l}$ for each side was administered, over a period of $2 \mathrm{~min}$, using a micropump (Harvard Apparatus, Holliston, MA, USA). The needle was left in place for an additional $30 \mathrm{~s}$ to allow drug diffusion. During the injection the mouse was freely moving in the holding cage.

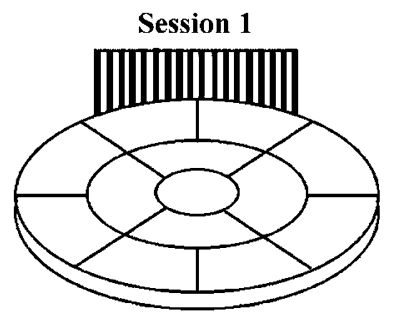

Session 2-4

Habituation phase

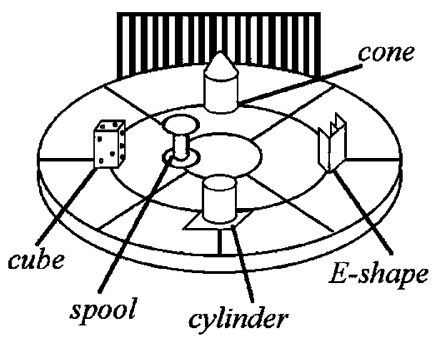

Session 5

Spatial change

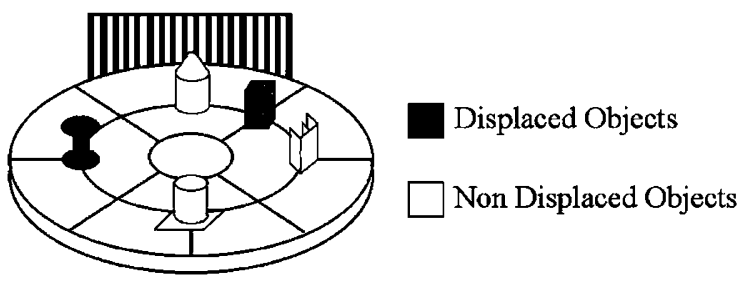

Session 6

Non-spatial change

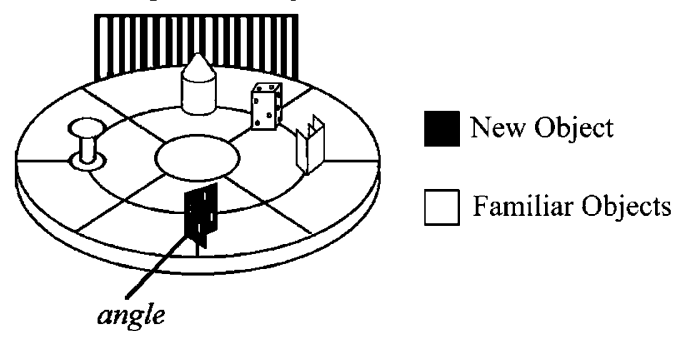

Figure I Experimental apparatus and behavioral testing procedure (see Materials and methods section for description).
At $5 \mathrm{~min}$ after the injection the mouse was placed in the open field for five consecutive $6 \mathrm{~min}$ sessions (S2-S6), separated by 2 min intervals during which the animal was returned to the holding cage. During sessions 2, 3 and 4 (habituation phase) five objects were placed in the open field, in the same position. In session 5 (spatial change session) two objects (cube and spool) were repositioned, thereby changing the spatial configuration of the objects in the open field. In session 6 (non-spatial change session) one of the familiar Non-Displaced Objects (NDO) (cylinder) was replaced by a novel object (angle) at the same location. The experimenter touched all objects before each session. The whole test lasted approximately $1 \mathrm{~h}$ and was conducted all in 1 day, during the light period (between 09:30 and 15:30).

\section{Histological Verification}

At the end of the experiment, mice were euthanized with an overdose of chloral hydrate $(800 \mathrm{mg} / \mathrm{kg})$ and the brain removed and stored in $4 \%$ formalin at $4{ }^{\circ} \mathrm{C}$. Coronal sections $(90 \mu \mathrm{m})$ were taken using a freezing microtome and stained with cresyl violet to visualize the injection site.

\section{Data Collection and Statistical Analysis}

Data collection was performed by a trained observer blind to drug treatment, with the use of a computer keyboard and specific software (Timer 1.3. for Mac, NIMH, Bethesda, MD, USA). In all sessions, locomotor activity was scored as the time the mouse spent walking or moving horizontally. Grooming, leaning (placing the forelimb against the wall of the open field) and rearing (standing on hind paws) were also scored in all sessions. During sessions S2-S6, object exploration was scored as the time the animal spent in contact with an object. A contact was defined as the mouse's snout actually touching an object (for details, see Save et al, 1992; Roullet et al, 1996; Sargolini et al, 1999).

Habituation to object exploration was assessed by considering the mean duration of contact with the five objects (total time of exploration/number of objects) during sessions 2, 3, and 4. Data were analyzed using factorial repeated-measure ANOVA with treatment as betweensubjects factor (four levels) and session as within-subjects factor (three levels).

On session 5, the spatial arrangement of the objects was modified and the reaction to the spatial change was assessed by considering the mean duration of contact with the DO and the NDO during the session 4 and 5. Data were analyzed using factorial repeated-measure ANOVA with treatment as a between-subjects factor (four levels) and object category (two levels) as within-subjects factor.

On session 6, a non-displaced object was substituted with a new object placed at the same location. The reaction to the non-spatial change was assessed by considering the mean time spent exploring the Novel Object (NO) and the Familiar Objects (FO) during the session 6. Data were analyzed using factorial repeated-measure ANOVA with treatment as the between-subjects factor (four levels) and object category (two levels) as within-subjects factor.

Moreover, an additional analysis was performed on the habituation-phase data, to make sure that no particular 
object was explored preferentially (between-subjects factor: treatment; within-subjects factors: session and object type).

A simple effect analysis or a Tukey's HSD (honestly significant difference) post hoc comparison was performed when allowed. Level of significant was set at $P<0.05$.

\section{RESULTS}

\section{Histological Verification}

Figure 2 shows the distribution of injector tip placements (approximately $0.8 \mathrm{~mm}$ below cannula tips) mapped on a schematic representation of a mouse brain coronal section (Franklin and Paxinos, 1997). Only mice with correct injector sites were included in the statistical analysis.

\section{Locomotor Activity in Session 1}

In Table 1, the activity levels of mice before drug administration, in both experiments 1 and 2, are reported. All groups showed similar levels of locomotor activity (Experiment 1: $F_{(3,43)}=1.71, \mathrm{NS}$; Experiment 2: $F_{(3,41)}=2.35$, NS). During session 1 grooming, rearing and leaning behaviors were also scored (data not shown). The ANOVA revealed no significant differences between groups, separately for each experiment (Experiment 1: grooming
$F_{(3,43)}=0.61$, NS; rearing $F_{(3,43)}=2.51$, NS; leaning $F_{(3,43)}=0.69$, NS; Experiment 2: grooming $F_{(3,41)}=0.50$, NS; rearing $F_{(3,41)}=6.69$, NS; leaning $F_{(3,41)}=2.70$, NS).

\section{Experiment 1. Effect of D1 Antagonist Focal Administration into the Prelimbic Region of PFC on Locomotor Activity and Habituation}

Figure 3a shows the effects of SCH 23390 on locomotor activity in each session after the injection (S2-S6). SCH 23390 injection did not produce any significant change. All groups showed a progressive decrease of locomotor activity over the sessions. The ANOVA revealed a significant effect of the factor session $\left(F_{(4,172)}=10.32, P<0.001\right)$, but not a treatment effect $\left(F_{(3,43)}=1.03, \mathrm{NS}\right)$ nor a significant interaction between the two factors $\left(F_{(12,172)}=0.99, \mathrm{NS}\right)$.

The time spent exploring each object during the habituation phase was analyzed to verify that there was no preferential exploration of any object (data not shown). The ANOVA revealed no significant interaction between the factors treatment, session and object type $\left(F_{(24,344)}=1.16\right.$; NS $)$.

Figure $3 \mathrm{~b}$ shows the mean levels of exploration of all the five objects during the three habituation sessions (S2-S4). Control animals showed a decrease of objects exploration from session 2 to 4 . The habituation curves of groups
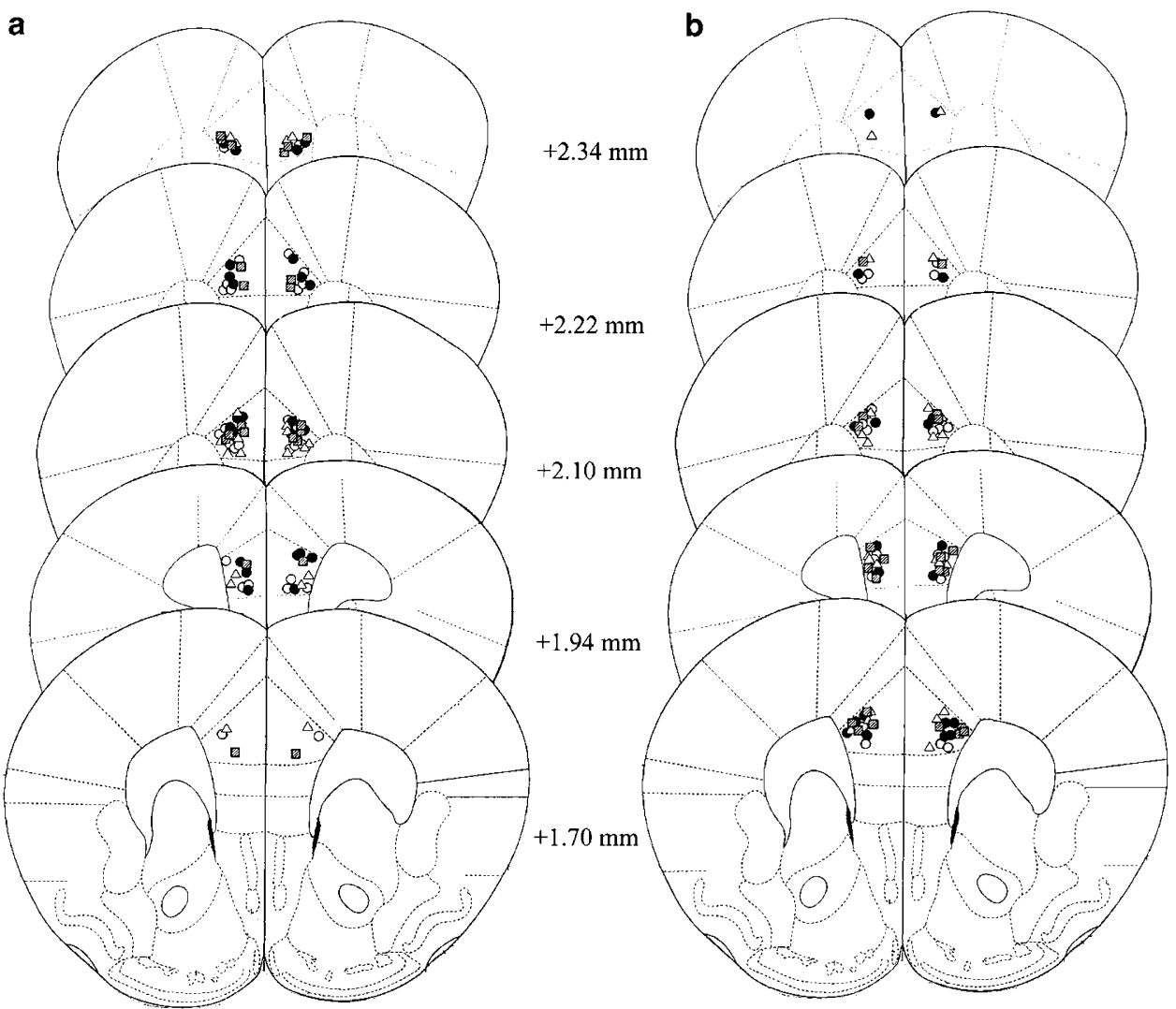

Figure 2 Schematic representation of the injection sites in all experiments, mapped on drawings of mouse brain coronal sections (adapted from Franklin and Paxinos, 1997). Each symbol represents the approximate injector tip placement for one animal. The values indicate the distance from bregma. All groups were homogeneously distributed across antero-posterior coordinates from +1.70 to +2.34 . Only data from animals with injection sites located in the PL region of the PFC were included in the statistical analysis. (a) Experiment I: $\bigcirc$ saline, $n=14 ;-\mathrm{SCH} 233906.25 \mathrm{ng} / \mathrm{side}, \mathrm{n}=\mathrm{I2}$; $\boldsymbol{\Delta} \mathrm{SCH} 23390$ I2.5 ng/ side, $n=10$; $\mathrm{SCH} 2339050 \mathrm{ng} / \mathrm{side}, n=1 \mathrm{I}$. (b) Experiment 2: $\bigcirc$ vehicle, $n=12 ; 0$ sulpiride $12.5 \mathrm{ng} / \mathrm{side}, n=10 ; \boldsymbol{\Delta}$ sulpiride $50 \mathrm{ng} / \mathrm{side}, n=12$; sulpiride $100 \mathrm{ng} /$ side, $n=11$. 
Table I Locomotor Activity in the Experimental Groups in SI, before Drug Administration

$\begin{array}{ll}\text { Experiment I } & \\ \text { Saline } & 154.56 \pm 7.96 \\ \text { SCH23390 } 6.25 & |28.45 \pm 6.9| \\ \text { SCH23390 } 12.5 & \mid 44.19 \pm 6.47 \\ \text { SCH23390 } 50 & |43.16 \pm| 1.82\end{array}$

\section{Experiment 2}

Vehicle

$114.46 \pm 10.41$

Sulpiride 12.5

$146.17 \pm 8.83$

Sulpiride 50

$132.98 \pm 7.79$

Sulpiride 100

$139.99 \pm 8.58$

Data are expressed as mean time (s) \pm SEM.
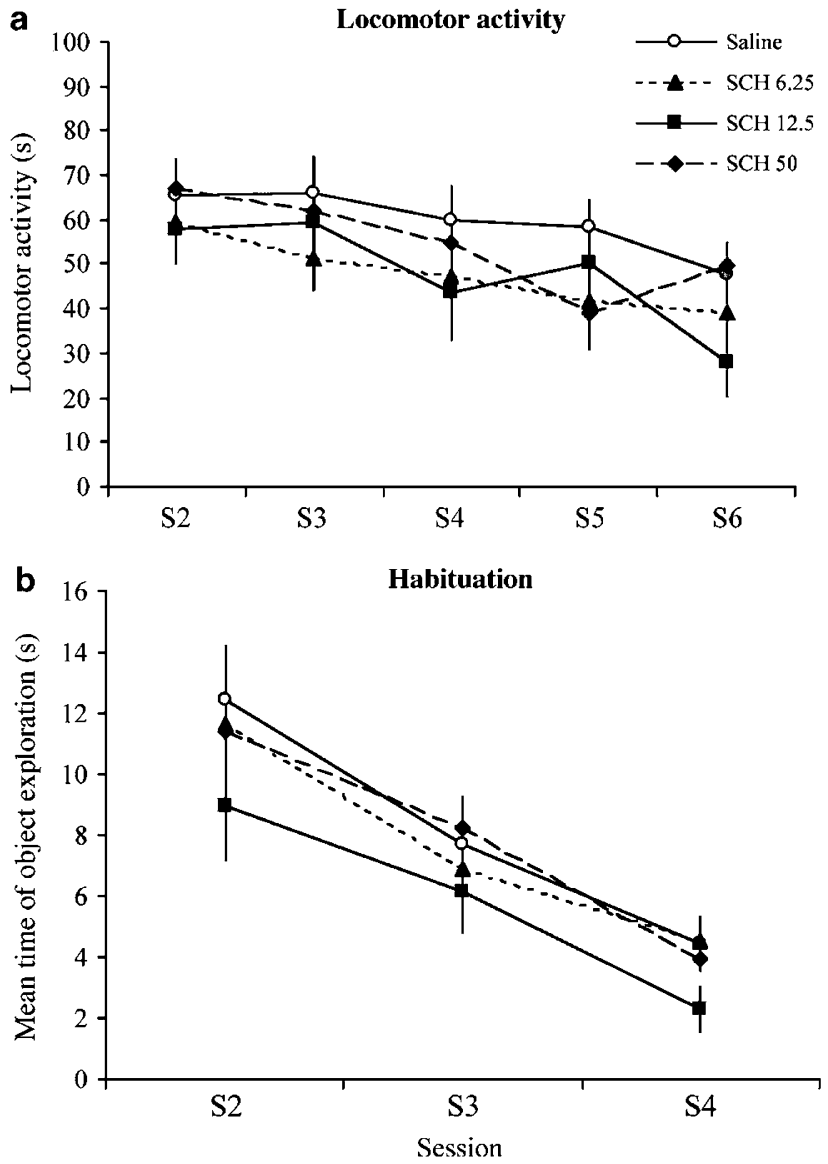

Figure 3 Effect of focal administration of the DI receptor antagonist SCH 23390 (SCH) into the prelimbic region of PFC on locomotor activity (a) and object exploration during the habituation phase (b). Symbols represent mean (s) \pm SEM. Saline, $n=14$; SCH 233906.25 ng/side, $n=12$; SCH 2339012.5 ng/side, $n=10 ;$ SCH 2339050 ng/side, $n=11$.

treated with the different doses of SCH 23390 did not differ from those of the saline-treated mice. The statistical analysis revealed a significant session effect $\left(F_{(2,86)}=\right.$ 43.60, $P<0.001)$, but no significant effect of treatment $\left(F_{(3,43)}=1.40, \mathrm{NS}\right)$ or of their interaction $\left(F_{(6,86)}=0.26, \mathrm{NS}\right)$.
Experiment 1. Effect of D1 Antagonist Focal Administration into the Prelimbic Region of PFC on Reaction to a Spatial and a Non-Spatial Change

Blockade of D1 receptors in the PFC impaired the ability of mice to react to a spatial change. The effect of SCH 23390 on reaction to a spatial change is shown in Figure 4a. Data are expressed as mean levels of exploration of DO and NDO in the last session of habituation (S4) and in the session of spatial change (S5). In session 4 all mice explored the two categories of object (DO and NDO) for a similar amount of time (ANOVA: object category $F_{(1,43)}=3.76$, NS; treatment $F_{(3,43)}=1.51$, NS; object category $\times$ treatment $F_{(3,43)}=1.35$, NS). In session 5, saline-treated animals and those injected with the lower dose of the drug spent more time exploring DO compared to NDO, on the other hand the animals treated with the two higher doses of SCH 23390 showed similar levels of exploration of both the object categories. The ANOVA revealed in fact a significant interaction effect (object category $F_{(1,43)}=26.92, P<0.001$; treatment $F_{(3,43)}=0.41$, NS; treatment $\times$ object category $F_{(3,43)}=3.58$, $P<0.05)$. This was confirmed by the post hoc analysis that showed a significant difference only for saline $(P<0.001$, Tukey's HSD) and SCH 6.25-treated mice $(P<0.005$, Tukey's HSD) but not for animals administered with $\mathrm{SCH}$ 12.5 ( $P=0.99$, Tukey's HSD) or SCH $50(P=0.97$, Tukey's HSD).

Drug treatment did not induce any impairment in the ability of mice to react to a non-spatial change. Figure $4 \mathrm{~b}$ shows the effect of SCH 23390 on the reaction to a nonspatial change. In session 6, when a familiar object is substituted by a new one, all animals spent significantly more time exploring the Novel Object (NO) compared to the Familiar Objects (FO) (ANOVA: object category $\left.F_{(1,43)}=81.57, P<0.001\right)$. The statistical analysis revealed no significant effect of treatment $\left(F_{(3,43)}=1.32, \mathrm{NS}\right)$ nor of the interaction between the two factors $\left(F_{(3,43)}=1.82\right.$, NS).

\section{Experiment 2. Effect of D2 Antagonist Focal Administration into the Prelimbic Region of PFC on Locomotor Activity and Habituation}

The effect of focal administration of sulpiride on locomotor activity from session 2-6 (S2-S6) is shown in Figure 5a. Sulpiride injection in the prelimbic PFC did not affect locomotor activity (ANOVA: treatment $F_{(3,41)}=0.17$, NS) and all groups showed a significant decrease of locomotion over sessions (ANOVA: session $F_{(4,164)}=19.09, P<0.001$ ). The ANOVA revealed no significant interaction between the factors treatment and session $\left(F_{(12,164)}=0.70, \mathrm{NS}\right)$.

During the habituation phase all animals explored each object for a similar amount of time, not showing any preference (data not shown). The ANOVA revealed no significant interaction between the factors treatment, session and object type $\left(F_{(24,328)}=0.41, \mathrm{NS}\right)$.

The mean levels of exploration of the five objects during the three habituation sessions (S2, S3, S4) did not differ between control mice and sulpiride-administered mice and all groups showed the expected decrease in objects exploration from sessions 2-4 (Figure 5a) (ANOVA: treatment $F_{(3,41)}=1.51$, NS; session $F_{(2,82)}=41.71, P<0.001$; treatment $\times$ session $\left.F_{(6,82)}=0.33, \mathrm{NS}\right)$. 
a

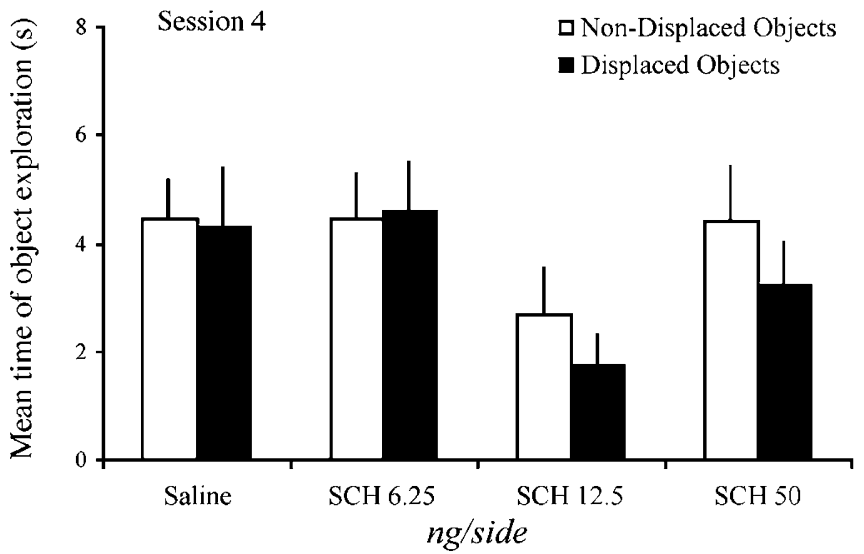

Spatial change

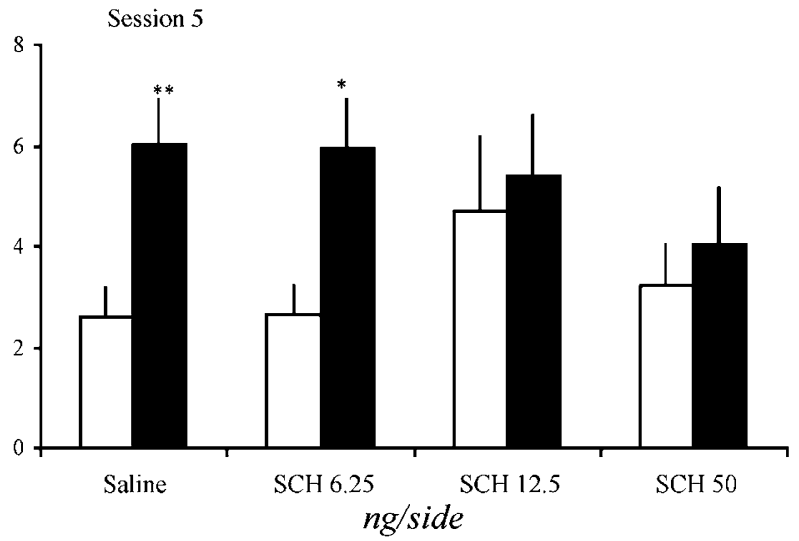

b

Non-spatial change

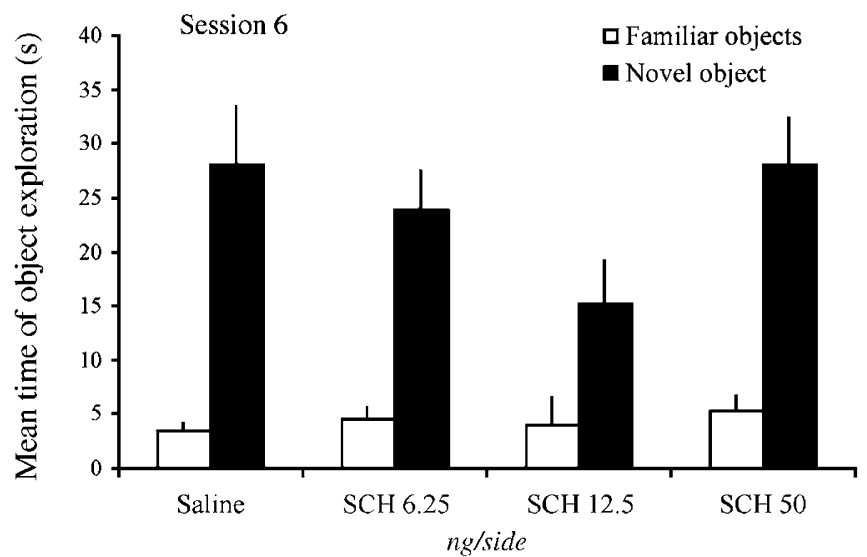

Figure 4 Effect of focal administration of the DI receptor antagonist $\mathrm{SCH} 23390$ (SCH) into the prelimbic region of PFC on reaction to a spatial (a) and a non-spatial change (b). Bars represent the mean time spent exploring the two categories of object (s) $\pm S E M$. $* P<0.005$, *** $P<0.00$ I for NDO vs DO within the same experimental group (Tukey's HSD post hoc). Saline, $n=14$; SCH $233906.25 \mathrm{ng} / \mathrm{side}, n=12 ; \mathrm{SCH} 23390$ I $2.5 \mathrm{ng} / \mathrm{side}, n=10$; SCH $2339050 \mathrm{ng} /$ side, $n=||$.

\section{Experiment 2. Effect of D2 Antagonist Focal Administration into the Prelimbic Region of PFC on Reaction to a Spatial and a Non-Spatial Change}

Blockade of $\mathrm{D} 2$ receptors in the $\mathrm{PL}$ region of the $\mathrm{PFC}$ impaired the ability of mice to react to a spatial change. Figure 6a shows the effect of sulpiride on the reaction to a spatial change. Data are expressed as mean levels of exploration of DO and NDO in the last session of habituation (S4) and in the session of spatial change (S5). In session 4, all groups did not differ in the exploration of the DO $v s$ NDO (ANOVA: treatment $F_{(3,41)}=1.04$, NS; object category $F_{(1,41)}=0.48, \mathrm{NS}$; treatment $\times$ object category $\left.F_{(3,41)}=0.17, \mathrm{NS}\right)$. In the session of spatial change, vehicle-treated animals spent significantly more time exploring DO compared to NDO. The group administered with the lower dose of sulpiride also showed a selective exploration of the DO. On the contrary, mice treated with the two higher doses of D2 antagonist spent a similar amount of time exploring the two object categories. The ANOVA revealed a significant object category effect $\left(F_{(1,41)}=16.87, P<0.001\right)$, no significant treatment effect $\left(F_{(3,41)}=0.09\right.$, NS) but a significant interaction between the factors treatment and object category $\left(F_{(3,41)}=4.92\right.$, $P<0.01)$. The post hoc analysis confirmed that the difference in the exploration of the two category of objects in S5 was significant for mice treated with vehicle $(P<0.005$, Tukey's HSD), shortly failed to reach significance for sulpiride $12.5(P=0.058$, Tukey's HSD $)$ and was not significant for sulpiride $50(P=0.86$, Tukey's HSD $)$ and sulpiride 100 -treated mice ( $P=0.99$, Tukey's HSD).

Sulpiride treatment did not induce any impairment in the ability of mice to react to a non-spatial change. Figure $6 \mathrm{~b}$ shows the effect of sulpiride on the reaction to a non-spatial change. In session 6 all groups showed a selective exploration of the Novel Object (NO) compared to the Familiar Objects (FO). (ANOVA: object category $F_{(1,41)}=$ 26.74, $P<0.001$; treatment $F_{(3,41)}=0.27$, NS; treatment $\times$ object category $F_{(3,41)}=0.26$, NS).

\section{DISCUSSION}

In this study, we demonstrate that blockade of both D1 and D2 dopamine receptors in the PL region of the PFC produce a specific impairment in the ability of mice to react to a 

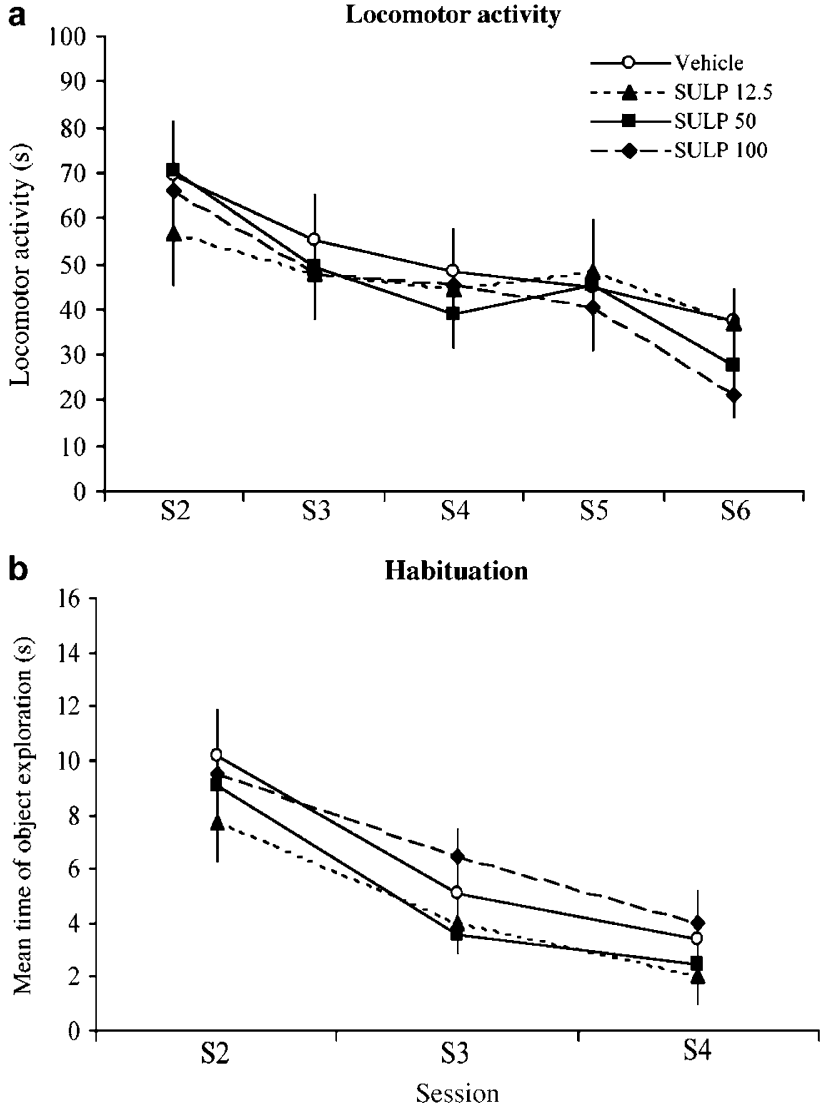

Figure 5 Effect of focal administration of the D2 receptor antagonist sulpiride (SULP) into the prelimbic region of PFC on locomotor activity (a) and object exploration during the habituation phase (b). Symbols represent mean (s) \pm SEM. Vehicle, $n=12$; sulpiride $12.5 \mathrm{ng} /$ side, $n=10$; sulpiride $50 \mathrm{ng} / \mathrm{side}, n=12$; sulpiride $100 \mathrm{ng} / \mathrm{side}, n=11$.

spatial change, thus indicating the involvement of the mesocortical dopaminergic system in spatial learning.

In both experiments, during the three sessions of habituation (S2-S4) control mice spent progressively less time exploring the objects in the open field, habituating to the environment and to the objects' configuration. In session 4, the animals explored the objects that were to be displaced and the objects that were to remain in the same position in the subsequent session for a similar amount of time. This indicates that there was no preference for either the position of the objects or for any of the objects per se. In session 5 , when two objects were displaced, the mice reacted by exploring the DO more than the NDO. Finally, when in session 6 a novel object was substituted for a familiar one, a selective exploration of the novel object was observed. The increased exploration of the DO in session 5 is generally interpreted as the ability of the animals to detect a spatial change in the environment, comparing the new arrangement of the objects with an internal representation of the initial spatial configuration (Poucet, 1989; Roullet et al, 1996; Thinus-Blanc et al, 1992). In session 6, the object arrangement was not changed, thus the ability of mice to perceive a non-spatial change in this session represents a way to assess their ability to detect a general environmental change (Sargolini et al, 1999).
In the first experiment, we studied the effect of bilateral focal administration of the D1 receptor antagonist $\mathrm{SCH}$ 23390 in the prelimbic region of the PFC. The blockade of prefrontal D1 receptors did not affect any of the parameters of general activity measured, such as locomotion, grooming, rearing or leaning behaviors. The time spent by the $\mathrm{SCH}$ 23390-treated animals exploring the objects during the habituation phase (S2-S4) was not different from that of saline-injected mice and also the habituation pattern was not affected by the drug. The main effect found was a deficit in the ability of the mice to react to the spatial change. In fact, the groups administered within the PFC with the two highest doses of the D1 antagonist explored the two object categories, DO and NDO, for a similar amount of time, not showing any selectivity. Finally, the drug treatment did not impair the ability of the mice to react to a non-spatial change, as in session 6 SCH 23390-treated animals, similar to saline controls, spent significantly more time exploring the novel compared to the familiar objects. Thus, on the basis of the present results, blockade of D1 receptors within the PFC seems to induce a selective deficit in the ability of mice to react to the spatial displacement suggesting a role of these receptors in modulating the acquisition/transmission of spatial information.

It should be mentioned that SCH 23390 acts not only as a D1 receptor antagonist, but also as a 5-HT2 receptor competitive antagonist (Ohlstein and Berkowitz, 1985; Bischoff et al, 1986). To our knowledge, there have been no published studies on the role of 5-HT2 receptor in the PFC, in spatial learning in rodents. Nevertheless, the effects observed after systemic administration of 5-HT2 agonists or antagonists on spatial learning and memory do not support the possibility that the deficit observed in this study could be due to blockade of 5-HT2 receptors. In fact, it has been reported that 5-HT2 agonists impair (Kant et al, 1998), while antagonists, such as ketanserin and methiothepin, have no effect on the ability of animals to acquire spatial information in the Morris water maze (Dringenberg and Zalan, 1999).

In the second experiment, we found that focal administration of the D2 receptor antagonist sulpiride in the prelimbic region of the PFC, induces a deficit on spatial learning. As for experiment 1, the deficit in the ability of mice to react to the spatial change seems to be due to an impaired ability to encode or use information relative to spatial relationships among objects in the open field. Indeed all other behavioral parameters measured in the present study were not affected by the treatment. Sulpiride administration, in fact, did not affect locomotor activity, leaning, rearing and grooming behaviors. Also, no significant difference was observed between sulpirideadministered mice and control mice in the exploration of all the objects during the habituation phase. Finally, in session 6 sulpiride-treated animals did not significantly differ from saline-injected mice in the time spent exploring the novel object.

The present results confirm and extend previous findings reported by us and others suggesting an involvement of the PFC in spatial learning. For example, using the same nonassociative task used in the present study, it has been demonstrated that ibotenic acid lesions of the PFC induce a selective impairment in the ability of mice to detect a spatial 


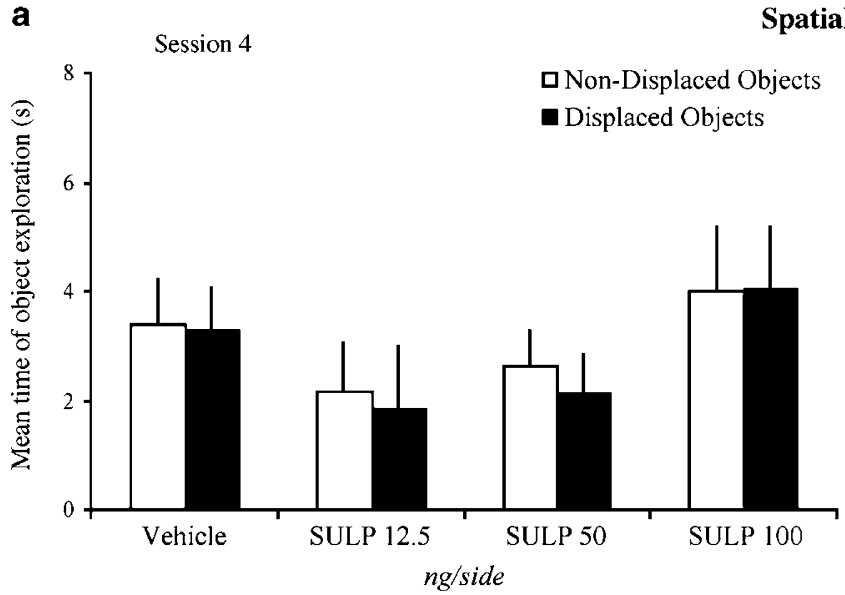

Spatial change

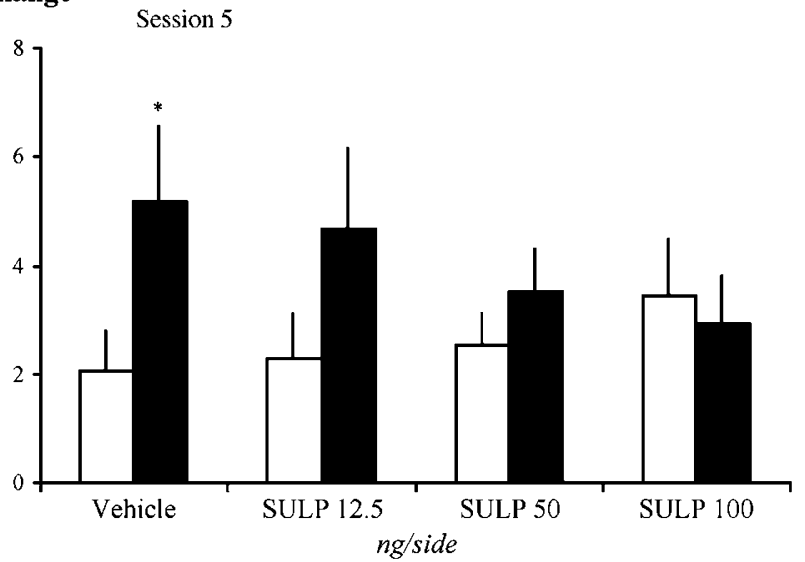

b Non-spatial change

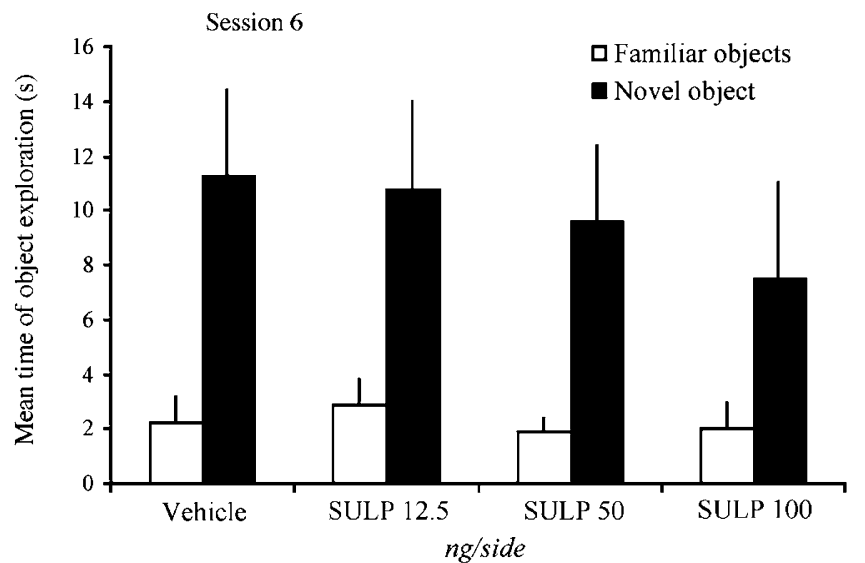

Figure 6 Effect of focal administration of the D2 receptor antagonist sulpiride (SULP) into the prelimbic region of PFC on reaction to a spatial (a) and a non-spatial change (b). Bars represent the mean time spent exploring the two categories of object (s) \pm SEM. *P $<0.005$ for NDO vs DO within the same experimental group (Tukey's HSD post hoc). Vehicle, $n=12$; sulpiride $12.5 \mathrm{ng} / \mathrm{side}, n=10$; sulpiride $50 \mathrm{ng} / \mathrm{side}, n=12$; sulpiride $100 \mathrm{ng} / \mathrm{side}, n=11$.

change (Sargolini et al, 1999). Furthermore, in rats, lesions of the PFC have been shown to disrupt performance in the delayed spatial win-shift version of the radial-arm maze task (Seamans et al, 1995; Floresco et al, 1997), in the Morris water maze task (Sutherland et al, 1982; Kolb, 1984) and in the delayed spatial alternation task (de Brabander et al, 1991; Sanchez-Santed et al, 1997). It should be mentioned, however, that the literature is not always consistent in demonstrating impairments after prefrontal cortical lesions. In fact, a lack of effect of PFC manipulation has been reported in rats both in the Morris water maze (de Bruin et al, 1994) as well as in an object displacement task similar to the one used in the present study (Poucet, 1989). These discrepancies have been explained on the basis of procedural differences involving short $v s$ long-term memory (de Bruin et al, 1994, 2001). While the present experiments were not designed to address these issues, a deficit in short-term memory independent of the kind of information would have been expected to also impair novel object discrimination in session 6 and this was not the case.

Neuroanatomical studies, carried out mostly in rats, demonstrate that in the PFC glutamate projections from the hippocampus constitute asymmetric synaptic contacts with
DA terminals on the same pyramidal cells (Van Eden et al, 1987; Carr and Sesack, 1996). Additionally, binding studies suggest that D1 and D2 receptors might be localized on different populations of pyramidal and nonpyramidal neurons in the PFC, partially overlapping on nonpyramidal neurons (Vincent et al, 1993, 1995; Gaspar et al, 1995). In this framework, although there are not exhaustive studies about the ultrastructure of the prefrontal dopaminergic system in mice, it seems conceivable that dopamine could modulate the transmission of spatial information acting at a post-synaptic level on pyramidal neurons receiving hippocampal projections. It should be mentioned, however, that the kind of modulatory effect that DA can exert on these neurons is rather controversial (Penit-Soria et al, 1987; Godbout et al, 1991; Yang and Seamans, 1996; Zheng et al, 1999; Wang and O’Donnell, 2001). Several electrophysiological studies have noted, in fact, a complex neuromodulation of DA over PFC activity. In particular, D1 receptor activation has generally been shown to enhance glutamate induced post-synaptic activity (Wang and O'Donnell, 2001; Wirkner et al, 2004) while data regarding the effects induced by $\mathrm{D} 2$ receptor activation are more contradictory (Pirot et al, 1992; Zheng et al, 1999; Wirkner et al, 2004). 
From a behavioral point of view, it has been reported that PFC focal administrations of D1 antagonists induce deficits in the ability to use spatial information to guide foraging behavior in rats (Seamans et al, 1998) and in an oculomotor delayed-response task in non-humans primates (Sawaguchi and Goldman-Rakic, 1994). Thus, consistent with the electrophysiological findings, behavioral evidence supports a facilitatory effect of D1 receptors on PFC activity. The results we present in this study are in line with these observations confirming that impaired activity of D1 receptors induces deficits in the processing of spatial information.

Interestingly, we also found a deficit after sulpiride administration indicating that activation of both receptors subtypes within this structure is needed in order to properly encode or transmit spatial information. This observation seems to contradict the different effects induced by D1/D2 receptors manipulations on PFC pyramidal neurons activity (Gulledge and Jaffe, 1998; Zheng et al, 1999; Henze et al, 2000; Wirkner et al, 2004). Although few studies have addressed this issue, D2 receptor antagonists have been generally found to be void of effects in different behavioral tasks when focally administered within the PFC (Seamans et al, 1998; Romanides et al, 1999). In order to reconcile our results with the biochemical and the electrophysiological findings, we postulate that cooperation between the two receptor subtypes, in the same or on different neuronal population, would be required for accurate task-relevant information processing. It is worth noting that recently Floresco et al (2006) suggested that D1 and D2 dopamine receptors might cooperate within the PFC to favor setshifting. However, even if it is difficult to exclude that the effects observed in the present study could be partially due to alteration in set-shifting, if the effect observed was solely due to impairment in behavioral flexibility a reduction in the exploration of the novel object in S6 should have also been observed, in both experiments and this was not the case. Thus, on the one hand the present results support the suggestion of a cooperation between the two receptor subtypes within the PFC, on the other hand they expand this observation suggesting that it could be relevant in the modulation of different behavioral responses. Alternatively, it could be speculated that the two receptor subtypes within the PFC might differentially modulate distinct aspects of the process. Indeed, it should be considered that the procedure used in the present study involves the administration of the drug before training, thus not allowing a determination of which of the different aspects of the process required to discriminate object displacement (eg acquisition, recall of spatial information, executive or motor functions) might have been affected by the drugs. This latter hypothesis seems to be supported by two types of evidence: altered extracellular DA levels in rats prelimbic cortex in different phases (acquisition and test) of a spatial task (Phillips et al, 2004); the differential effects induced by iontophoretic application of selective DA drugs to prefrontal neurons recorded during an oculomotor delayed-response task in non-human primates (Williams and Goldman-Rakic, 1995; Wang et al, 2004). In particular, these latter studies have demonstrated that D1 receptor manipulations affect directional delay-related activity of single PFC neurons during the task, while D2 receptor manipulation affects selectively the activity of response-related neurons (Williams and Goldman-Rakic, 1995; Sawaguchi, 2001; Wang et al, 2004). On the basis of our results both the hypotheses are likely. Further neuropharmacological studies involving focal administrations of DA acting drugs, using independent procedures, will be needed to address this issue.

The present study is a further extension of a previous report from our laboratory investigating the role of the mesoaccumbens dopaminergic system in spatial learning (Coccurello et al, 2000). We have shown that intraaccumbens focal injection of the D1 antagonist $\mathrm{SCH}$ 23390 selectively impairs the ability of mice to detect a spatial change, while administration of the D2 antagonist sulpiride induces a general impairment of locomotor activity, object exploration and reaction to both spatial and non-spatial changes (Coccurello et al, 2000). Comparison of the effects induced by D1 and D2 DA receptor manipulation within the two structures on the one hand indicates an involvement of both regions in the short-term transmission/encoding of visuo-spatial information, thus supporting previous observations suggesting that such processes involve an interaction of several brain regions within an integrated circuit (Wise et al, 1996; Floresco et al, 1997; Sargolini et al, 1999). On the other hand, it raises other interesting questions regarding the role of the two structures and of the two DA receptor subtypes within these structures in mediating transmission/encoding of this information. Indeed it is interesting to note that administrations of the D1 receptor antagonist induced similar behavioral patterns (ie a selective impairment in the reactivity to the spatial change) when injected into the PFC or the nucleus accumbens. There is now consistent experimental evidence suggesting that striatal glutamate receptor-channels undergo states of phosphorylation and dephosphorylation that can prolong or shorten the time of activation of the channels (Colwell and Levine, 1995; Umemiya and Raymond, 1997) and that these changes are under the control of D1 DA receptors (Chao et al, 2002). Such processes could explain the facilitatory effects of D1 receptors on the short-term processing of spatial information in the two structures.

On the other hand, the D2 receptor, in contrast to the D1 receptor antagonist, induce a different pattern of behavioral response when injected into the two structures. In fact, injections into the PFC induced a selective impairment in the reactivity to the spatial change while administrations into the nucleus accumbens exerted a more general behavioral impairment (Coccurello et al, 2000). In light of the different working hypotheses on PFC and nucleus accumbens functions (Wise et al, 1996; Robbins and Everitt, 2002) this observation is not surprising and it prompts the suggestion that D2 antagonist-induced effects could reflect a general modulatory action of these receptors on these two structures rather than a selective modulation of specific processes needed for the encoding/transmission of visuospatial information.

Prefrontal dysfunction have been associated with several psychiatric disorders (Levin, 1984; Weinberger et al, 1992; Zang et al, 2005). The present data suggest that both D1 and D2 receptors within the $\mathrm{PFC}$ might have an important role in the neural mechanisms underlying cognitive deficits in such diseases. 


\section{ACKNOWLEDGEMENTS}

Thanks to Dr Agu Pert for his suggestions on a previous version of the manuscript and $\mathrm{Mr}$ Tullio Riosa and Mr Genesio Ricci for their technical assistance. This study was partially supported by MIUR with PRIN grants to AO and AM, with a FIRB grant to $\mathrm{AO}$ and by a grant from ' $\mathrm{La}$ Sapienza' University of Rome to AO.

\section{REFERENCES}

Adriani W, Sargolini F, Coccurello R, Oliverio A, Mele A (2000). Role of dopaminergic system in reactivity to spatial and nonspatial changes in mice. Psychopharmacology 150: 67-76.

Berger B, Tassin JP, Blanc G, Moyne MA, Thierry AM (1974). Histochemical confirmation for dopaminergic innervation of the rat cerebral cortex after destruction of the noradrenergic ascending pathways. Brain Res 81: 332-337.

Bischoff S, Heinrich M, Sonntag JM, Krauss J (1986). The D-1 dopamine receptor antagonist SCH 23390 also interacts potently with brain serotonin (5-HT2) receptors. Eur J Pharmacol 129: 367-370.

Brito GN, Brito LS (1990). Septohippocampal system and the prelimbic sector of frontal cortex: a neuropsychological battery analysis in the rat. Behav Brain Res 36: 127-146.

Carr DB, Sesack SR (1996). Hippocampal afferents to the rat prefrontal cortex: synaptic targets and relation to dopamine terminals. J Comp Neurol 369: 1-15.

Chao SZ, Lu W, Lee HK, Huganir RL, Wolf ME (2002). D(1) dopamine receptor stimulation increases GluR1 phosphorylation in postnatal nucleus accumbens cultures. J Neurochem 81: 984-992.

Coccurello R, Adriani W, Oliverio A, Mele A (2000). Effect of intra-accumbens dopamine receptor agents on reactivity to spatial and non-spatial changes in mice. Psychopharmacology 152: 189-199.

Colwell CS, Levine MS (1995). Excitatory synaptic transmission in neostriatal neurons: regulation by cyclic AMP-dependent mechanisms. J Neurosci 15: 1704-1713.

Dawson TM, Gehlert DR, McCabe RT, Barnett A, Wamsley JK (1986). D-1 dopamine receptors in the rat brain: a quantitative autoradiographic analysis. J Neurosci 6: 2352-2365.

de Brabander JM, de Bruin JP, van Eden CG (1991). Comparison of the effects of neonatal and adult medial prefrontal cortex lesions on food hoarding and spatial delayed alternation. Behav Brain Res 42: 67-75.

de Bruin JP, Moita MP, de Brabander HM, Joosten RN (2001). Place and response learning of rats in a Morris water maze: differential effects of fimbria fornix and medial prefrontal cortex lesions. Neurobiol Learn Mem 75: 164-178.

de Bruin JP, Sanchez-Santed F, Heinsbroek RP, Donker A, Postmes $P$ (1994). A behavioral analysis of rats with damage to the medial prefrontal cortex using the Morris water maze: evidence for behavioral flexibility, but not for impaired spatial navigation. Brain Res 652: 323-333.

Delatour B, Gisquet-Verrier P (1996). Prelimbic cortex specific lesions disrupt delayed-variable response tasks in the rat. Behav Neurosci 110: 1282-1298.

Dringenberg HC, Zalan RM (1999). Serotonin-dependent maintenance of spatial performance and elettroencephalography activation after cholinergic blockade: effects of serotoninergic receptor antagonists. Brain Res 837: 242-253.

El-Ghundi M, Fletcher PJ, Drago J, Sibley DR, O’Dowd BF, George SR (1999). Spatial learning deficit in dopamine $\mathrm{D}(1)$ receptor knockout mice. Eur J Pharmacol 383: 95-106.

Floresco SB, Magyar O, Ghods-Sharifi S, Claudia Vexelman C, Tse MTL (2006). Multiple dopamine receptor subtypes in the medial prefrontal cortex of the rat regulate set-shifting. Neuropsychopharmacology 31: 297-309.

Floresco SB, Seamans JK, Phillips AG (1997). Selective roles for hippocampal, prefrontal cortical, and ventral striatal circuits in radial-arm maze tasks with or without a delay. J Neurosci 17: $1880-1890$

Franklin BJ, Paxinos G (1997). The Mouse Brain in Stereotaxic Coordinates. Academic Press: San Diego.

Gaspar P, Bloch B, Le Moine C (1995). D1 and D2 receptors gene expression in the rat frontal cortex: cellular localization in different classes of efferent neurons. Eur J Neurosci 7: 1050-1063.

Glickstein SB, Hof PR, Schmauss C (2002). Mice lacking dopamine D2 and D3 receptors have spatial working memory deficits. J Neurosci 22: 5619-5629.

Godbout R, Mantz J, Pirot S, Glowinski J, Thierry AM (1991). Inhibitory influence of the mesocortical dopaminergic neurons on their target cells: electrophysiological and pharmacological characterization. J Pharmacol Exp Ther 258: 728-738.

Granon S, Save E, Buhot MC, Poucet B (1996). Effortful information processing in a spontaneous spatial situation by rats with medial prefrontal lesions. Behav Brain Res 72: 147-154.

Gulledge AT, Jaffe DB (1998). Dopamine decreases the excitability of layer V pyramidal cells in the rat prefrontal cortex. J Neurosci 18: 9139-9151.

Henze DA, Gonzalez-Burgos GR, Urban NN, Lewis DA, Barrionuevo G (2000). Dopamine increases excitability of pyramidal neurons in primate prefrontal cortex. J Neurophysiol 84: 2799-2809.

Jay TM, Witter MP (1991). Distribution of hippocampal CA1 and subicular efferents in the prefrontal cortex of the rat studied by means of anterograde transport of Phaseolus vulgaris-leucoagglutinin. J Comp Neurol 313: 574-586.

Kant GJ, Wylie RM, Chu K, Ghosh S (1998). Effects of the serotonin agonists 8-OH-DPAT, buspirone, and DOI on water maze performance. Pharmacol Biochem Behav 59: 729-735.

Kolb B (1984). Functions of the frontal cortex of the rat: a comparative review. Brain Res Rev 8: 65-98.

Lacroix L, White I, Feldon J (2002). Effect of excitotoxic lesions of rat medial prefrontal cortex on spatial memory. Behav Brain Res 133: $69-81$.

Levin S (1984). Frontal lobe dysfunctions in schizophrenia-II. Impairments of psychological and brain functions. J Psychiatr Res 18: $57-72$.

Lidow MS, Goldman-Rakic PS, Gallager DW, Rakic P (1991). Distribution of dopaminergic receptors in the primate cerebral cortex: quantitative autoradiographic analysis using $[3 \mathrm{H}]$ raclopride, $[3 \mathrm{H}]$ spiperone and $[3 \mathrm{H}] \mathrm{SCH} 23390$. Neuroscience 40: 657-671.

Lidow MS, Koh PO, Arnsten AFT (2003). D1 dopamine receptor in the mouse prefrontal cortex: immunocytochemical and cognitive neuropharmacological analyses. Synapse 47: 101-108.

Lindvall O, Bjorklund A, Moore RY, Stenevi U (1974). Mesencephalic dopamine neurons projecting to neocortex. Brain Res 81: $325-331$.

Mele A, Castellano C, Felici A, Cabib S, Caccia S, Oliverio A (1996). Dopamine-N-methyl-D-aspartate interactions in the modulation of locomotor activity and memory consolidation in mice. Eur J Pharmacol 82: 43-58.

Ohlstein EH, Berkowitz BA (1985). SCH 23390 and SKF 83566 are antagonists at vascular dopamine and serotonin receptors. Eur J Pharmacol 108: 205-208.

Penit-Soria J, Audinat E, Crepel F (1987). Excitation of rat prefrontal cortical neurons by dopamine: an in vitro electrophysiological study. Brain Res 425: 263-274.

Phillips AG, Ahn S, Floresco SB (2004). Magnitude of dopamine release in medial prefrontal cortex predicts accuracy of memory on delayed response task. J Neurosci 24: 547-553. 
Pirot S, Godbout R, Mantz J, Tassin JP, Glowinski J, Thierry AM (1992). Inhibitory effects of ventral tegmental area stimulation on the activity of prefrontal cortical neurons: evidence for the involvement of both dopaminergic and GABAergic components. Neuroscience 49: 857-865.

Ploeger GE, Spruijt BM, Cools AR (1992). Effect of haloperidol on the acquisition of a spatial learning rask. Physiol Behav 52: 979-983.

Poucet B (1989). Object exploration, habituation, and response to a spatial change in rats following septal or medial frontal cortical damage. Behav Neurosci 103: 1009-1016.

Robbins TW (2000). Chemical neuromodulation of frontalexecutive functions in humans and other animals. Exp Brain Res 133: 130-138.

Robbins TW, Everitt BJ (1996). Neurobehavioral mechanisms of reward and motivation. Curr Opin Neurobiol 6: 228-236.

Robbins TW, Everitt BJ (2002). Limbic-striatal memory systems and drug addiction. Neurobiol Learn Mem 78: 625-636.

Romanides AJ, Duffy P, Kalivas PW (1999). Glutamatergic and dopaminergic afferents to the prefrontal cortex regulate spatial working memory in rats. Neuroscience 92: 97-106.

Roullet P, Mele A, Ammassari-Teule M (1996). Involvement of glutamatergic and dopaminergic systems in the reactivity of mice to spatial and non-spatial changes. Psychopharmacology 126: $55-61$.

Sanchez-Santed F, de Bruin JP, Heinsbroek RP, Verwer RW (1997). Spatial delayed alternation of rats in a T-maze: effects of neurotoxic lesions of the medial prefrontal cortex and of T-maze rotations. Behav Brain Res 84: 73-79.

Sargolini F, Roullet P, Oliverio A, Mele A (1999). Effects of lesions to the glutamatergic afferents to the nucleus accumbens in the modulation of reactivity to spatial and non-spatial novelty in mice. Neuroscience 93: 855-867.

Save E, Poucet B, Foreman N, Thinus-Blanc C (1992). Object exploration and reactions to spatial change and nonspatial changes in hooded rats following damage to parietal cortex or dorsal hippocampus. Behav Neurosci 106: 447-456.

Sawaguchi T (2001). The effects od dopamine and its antagonist on directional delay-period activity of prefrontal neuron in monkeys during an oculomotor delayed-response task. Neurosci Res 41: 115-128.

Sawaguchi T, Goldman-Rakic PS (1994). The role of D1-dopamine receptor in working memory: local injections of dopamine antagonists into the prefrontal cortex of rhesus monkeys performing an oculomotor delayed-response task. J Neurophysiol 71: 515-528.

Seamans JK, Floresco SB, Phillips AG (1995). Functional differences between the prelimbic and anterior cingulate regions of the rat prefrontal cortex. Behav Neurosci 109: 1063-1073.

Seamans JK, Floresco SB, Phillips AG (1998). D1 receptor modulation of hippocampal-prefrontal cortical circuits integrating spatial memory with executive functions in the rat. J Neurosci 18: 1613-1621.

Sutherland RJ, Kolb B, Whishaw IQ (1982). Spatial mapping: definitive disruption by hippocampal or medial frontal cortical damage in the rat. Neurosci Lett 3: 271-276.
Thinus-Blanc C, Durup M, Poucet B (1992). The spatial parameters encoded by hamsters during exploration: a further study. Behav Processes 26: 43-57.

Umemiya M, Raymond LA (1997). Dopaminergic modulation of excitatory postsynaptic currents in rat neostriatal neurons. J Neurophysiol 78: 1248-1255.

Van Eden CG, Hoorneman EM, Buijs RM, Matthijssen MA, Geffard M, Uylings HB (1987). Immunocytochemical localization of dopamine in the prefrontal cortex of the rat at the light and electron microscopical level. Neuroscience 22: 849-862.

Vincent SL, Khan Y, Benes FM (1993). Cellular distribution of dopamine D1 and D2 receptors in rat medial prefrontal cortex. J Neurosci 13: 2551-2564.

Vincent SL, Khan Y, Benes FM (1995). Cellular colocalization of dopamine D1 and D2 receptors in rat medial prefrontal cortex. Synapse 19: 112-120.

Wang J, O'Donnell P (2001). D(1) dopamine receptors potentiate NMDA-mediated excitability increase in layer $\mathrm{V}$ prefrontal cortical pyramidal neurons. Cereb Cortex 11: 452-462.

Wang M, Vijayraghavan S, Goldman-Rakic PS (2004). Selective D2 receptor actions on the functional circuitry of working memory. Science 303: 853-856.

Weinberger DR, Berman KF, Suddath R, Torrey EF (1992). Evidence of dysfunction of a prefrontal-limbic network in schizophrenia: a magnetic resonance imaging and regional cerebral blood flow study of discordant monozygotic twins. Am J Psychiatry 149: 890-897.

Whishaw IQ, Dunnett SB (1985). Dopamine depletion, stimulation or blockade in the rat disrupts spatial navigation and locomotion dependent upon beacon or distal cues. Behav Brain Res 18: $11-29$.

Williams GV, Goldman-Rakic PS (1995). Modulation of memory fields by dopamine D1 receptors in prefrontal cortex. Nature 376: $572-575$.

Wirkner K, Krause T, Koles L, Thummler S, Al-Khrasani M, Illes P (2004). D1 but not D2 dopamine receptors or adrenoceptors mediate dopamine-induced potentiation of $\mathrm{N}$-methyl-D-aspartate currents in the rat prefrontal cortex. Neurosci Lett 372: 89-93.

Wise RA (2004). Dopamine, learning and motivation. Nat Rev Neurosci 5: 483-494.

Wise SP, Murray EA, Gerfen CR (1996). The frontal cortex-basal ganglia system in primates. Crit Rev Neurobiol 10: 317-356.

Yang CR, Seamans JK (1996). Dopamine D1 receptor actions in layers V-VI rat prefrontal cortex neurons in vitro: modulation of dendritic-somatic signal integration. J Neurosci 16: 1922-1935.

Zahrt J, Taylor JR, Mathew RG, Arnsten AF (1997). Supranormal stimulation of D1 dopamine receptors in the rodent prefrontal cortex impairs spatial working memory performance. J Neurosci 17: 8528-8535.

Zang YF, Jin Z, Weng XC, Zhang L, Zeng YW, Yang L et al (2005). Functional MRI in attention-deficit hyperactivity disorder: evidence for hypofrontality. Brain Dev 27: 541-543.

Zheng P, Zhang XX, Bunney BS, Shi WX (1999). Opposite modulation of cortical $\mathrm{N}$-methyl-D-aspartate receptor-mediated responses by low and high concentrations of dopamine. Neuroscience 1: 527-535. 